\title{
The use of misoprostol and mifepristone in second trimester interruption of pregnancy: State of art
}

Marco Monti ${ }^{1}$, Valentina Tibaldi ${ }^{1}$, Giusi Santangelo ${ }^{1 *}$, Cristina Pajno ${ }^{1}$, Sara Corno ${ }^{1}$, Debora D'aniello ${ }^{1}$, Andrea Giannini ${ }^{1}$, Francesco Clemente $^{2}$, Carlotta Bracchi ${ }^{1}$, Vanessa Colagiovanni ${ }^{1}$, Giorgia Perniola ${ }^{1}$, Innocenza Palaia ${ }^{1}$, Violante Di Donato ${ }^{1}$, Angela Musella ${ }^{1}$, Roberto Brunelli ${ }^{1}$, Antonella Giancotti ${ }^{1}$, Ludovico Muzii ${ }^{1}$ and Pierluigi Benedetti Panici ${ }^{1}$

${ }^{1}$ Department of Gynecological and Obstetric Sciences, and Urological Sciences, University of Rome "Sapienza”, Umberto I Hospital, Rome, Italy

${ }^{2}$ University of Rome "Sapienza”, Rome, Italy

\begin{abstract}
The therapeutic abortion is the voluntary interruption of the pregnancy after ninety days. This kind of abortion was introduced to preserve the mother's health or to avoid the development of a fetus marked by malformations or serious illnesses. The pharmacological abortion induced by the drugs mifepristone and/or misoprostol represents the most commonly used procedure for medical intervention during pregnancy and is effective in $90 \%$ of cases. Second-trimester abortions account for 10 $15 \%$ of all abortions induced worldwide and are responsible for two-thirds of all major abortion-related complications. This article aims to provide basic information on the recommended regimes for second-trimester medical abortion and best management practices as targeted therapy is a stronghold in clinical practice with the aim of minimizing side effects and achieving maximum results.
\end{abstract}

\section{Introduction}

Therapeutic abortion is the voluntary interruption of pregnancy caused by certain medical treatments in order to preserve the health of the mother or to avoid the development of a fetus marked by malformations or serious diseases. The history of therapeutic abortion begins in Italy in 1978 with the law 194/1978 art. 6.

The law provides that the voluntary termination of pregnancy, after the first ninety days, can be practiced when the pregnancy or childbirth involve a serious danger to the life of the woman or when pathological processes are ascertained, including those relating to significant anomalies or malformations of the unborn child, which cause a serious danger to the physical or mental health of the woman.

Medical abortion during early pregnancy was first approved in France in 1988 (up to 49 days of amenorrhoea) followed by approval in the UK (1991) and Sweden (1992) (up to 63 days of amenorrhoea in both the countries). However, it was only in 1999-2000 that both early first and second trimester medical abortion with mifepristone and a prostaglandin analogue were approved in several other European countries [1].

The upper term of gestational age is not specified by law, which reports the term as the time in which there is the possibility of an autonomous life for the fetus. The prevalence of interruption of pregnancy upper 90 day of gestation increased in the time. In the 1999 the prevalence was of $1.8 \%$ less than 2008 when increased to $3 \%$, this gradual increase in second trimester abortion in some European countries is justified with wide-scale introduction of antenatal screening programs to detect fetal abnormalities such as anencephaly and cardiovascular and skeletal malformations [2].

Second trimester abortions constitute $10-15 \%$ of all induced abortions worldwide but are responsible for two-thirds of all major abortion-related complications [1].
This article aims to provide basic information on regimens recommended for second trimester medical abortion and best practice in management.

\section{Therapeutic scheme}

The scientific progress of recent years has changed the management of the abortion over 90 days. Before 2010 it was not unusual for an induction to continue even for 7 days, adding to the agony of the suffering of the woman, the increase of the gestational age and therefore the chances of the fetus to express characters of vitality. Today things are different. The most used protocol consists of the administration of a tablet of mifepristone $200 \mathrm{mg} 3$ times / day $(600 \mathrm{mg})$ followed after 36 hours by an oral or vaginal prostaglandin such as misoprostol $400 \mathrm{mcg}$ sublinguals or gemeprost $1 \mathrm{mg}$ to be repeated in the absence of abortive labor every 3 hours for three or four times up to the completion of the abortion. This protocol proves effective in addition $90 \%$ of cases. It is recommended to administer an injective antibiotic in the immediacy of abortion, followed by a lactation inhibitor and, where necessary, from anti-D immunoprophylaxis [3].

\section{Pharmacokinetics and pharmacodynamics}

Pharmacological abortion induced by the drugs mifepristone and / or misoprostol represents the most commonly used procedure

*Correspondence to: Giusi Santangelo, Department Maternal Infantile and Urological Sciences, University of Rome "Sapienza", Umberto I Hospital, Rome, Viale del Policlinico 155, 00161 Roma, Italy, E-mail: giusi.santangelo@uniroma1.it

Key words: fetal malformation, maternal health, interruption of pregnancy, target therapy, clinical practice

Received: March 13, 2020; Accepted: March 19, 2020; Published: March 23 , 2020 
for the medical intervention of pregnancy [4]. Mifepristone is an artificial steroid drug with anti-progesterone and anti-glucocorticoid actions. Given its pharmacology, it most likely affects the cervix and uterus favorably for termination and increases uterine sensitivity to prostaglandin analogue, misoprostol, whose favorable profile and low cost, compared to other prostaglandin analogues, have it made a common inductive agent for use in the second quarter [5].

Misoprostol is a prostaglandin E1 analogue commonly used in obstetrics for the management of postpartum hemorrhage, incomplete abortion, medical abortion in the first and second trimester, induction of labor and cervical maturation. Misoprostol can be used buccally, sublingually, rectally and vaginally [6].

For therapeutic abortion, performed after 12 weeks from the last menstrual period (LMP), the WHO recommends as a scheme the administration of $200 \mathrm{mg}$ of oral mifepristone followed by doses of misoprostol 24-48 hours later. If a treatment scheme is used which does not involve the use of Mifepristone, WHO recommends the administration of 400 micrograms of vaginal or sublingual misoprostol repeated every 3 hours for a maximum of five doses [7].

\section{Chemistry of mifepristone and misoprostol}

\section{Mifepristone}

After oral administration, mifepristone is absorbed in the gastrointestinal tract and undergoes a hepatic first pass effect. The plasma peak, which is detected after 2-3 hours from the administration, results to be $2.5 \mathrm{mg} / \mathrm{L}$ after single administration for doses of 100-800 $\mathrm{mg}$ and of $1.4-1.7 \mathrm{mg} / \mathrm{L}$ if administrations are performed repeated doses greater than $100 \mathrm{mg} /$ day [8]. Mifepristone binds preferentially to alphal acid glycoprotein and when the binding to this protein is saturated, the drug binds to albumin [9]. It is mainly oxidized by CYP3A4 [10] and probably by CYP3A5[11]. Thanks to the irreversible modification of the apoprotein located in the active site of the enzyme CYP3A4 it appears to be its inhibitor [12]. Mifepristone metabolites include hydroxy derivatives, mono- and dimethyl derivatives and show affinity for progestin receptors equal to $9-21 \%$ of that of the parent drug, playing a minor role in the antiprogestinic effect of mifepristone [13]. Instead they have an affinity for glucocorticoid receptors equal on average to $45-61 \%$ of that of mifepristone thus contributing, to a greater extent, to the antiglucocorticoid effects that are found following the administration of high doses of drug. Mifepristone is mainly excreted via the bile and about $90 \%$ of the dose is eliminated in the feces in 6-7 days. Renal clearance is to be considered negligible, suggesting an insignificant influence of renal function on the pharmacokinetics of mifepristone [14].

\section{Misoprostol}

Misoprostol differs structurally from prostaglandin E due to the presence of a methyl ester at C-1, which increases its anti-secretory potency, a methyl group at $\mathrm{C}-16$ and a hydroxyl group at C-16 instead of $\mathrm{C}-15$ which improve oral activity and safety profile and increase the duration of the action [15]. Misoprostol can be administered oral, vaginally, sublingually, buccally, and rectally in obstetric and gynecological applications. After oral administration, misoprostol is rapidly and almost completely absorbed from the gastrointestinal tract; undergoes a first-pass metabolism (de-esterification) and misoprostol is formed. The plasma peak after a single dose of 400 micrograms is reached in about 30 minutes [16]. After vaginal administration the plasma concentration gradually increases reaching its maximum level after 7080 minutes and slowly decreases with detectable drug levels even after
6 hours. There is a greater bioavailability of misoprostol if administered vaginally. However, the virgin absorption is variable and incomplete and this may be due to the change in vaginal $\mathrm{pH}$. The change in the amount of bleeding during abortion may also influence the absorption of misoprostol through the vaginal mucosa [17]. The sublingual misoprostol has the shortest time to reach the peak concentration, the maximum concentration and the greatest bioavailability compared to other routes. The plasma peak is reached in about 30 minutes and turns out to be more than the oral and vaginal administration thanks to the rapid absorption through the sublingual mucosa and the exclusion of the first-pass hepatic metabolism. The abundant supply of blood under the tongue and the relatively neutral $\mathrm{pH}$ in the oral cavity can be contributing factors [18]. For buccal administration it is necessary that the drug is placed between the teeth and the cheek and absorbed through the buccal mucosa. The plasma peak is reached in 75 minutes [18]. The rectal route of administration has an absorption curve similar to that of vaginal administration, but its bio-availability is only $1 / 3$ compared to vaginal administration [19]. Sublingual misoprostol has the shortest Tmax, is perhaps useful for clinical applications that require a fast onset of clinical action, such as postpartum hemorrhage or cervical priming. Vaginal misoprostol on the other hand, which has a high bioavailability and sustained serum level, is useful for indications that require a longer time for the manifestation of its clinical effects, like medical abortion. The absorption kinetics can also explain why some routes of administration are associated with a higher incidence of side effects. Sublingual administration, which gives the highest Cmax, is associated with highest incidence of side effects when compared to other routes [15] (Figure1).

\section{Indications and usage}

Although in most countries mifepristone followed by a prostaglandin analogue is approved for medical termination of early first trimester pregnancy, mifepristone with repeated doses of a prostaglandin analogue is also licensed and widely used for abortion of later pregnancies.

Studies carried out in many different countries provide evidence of the safety of medical abortion up to 24 weeks of pregnancy [20].

However, it should be noted that while the dose of mifepristone does not change, the dose of misoprostol needs to be modified according to gestational age. A higher total dose is often needed in the late first trimester compared to the early first trimester. During the second trimester, due to increased sensitivity of the uterine muscles to PGs, lower doses are sufficient. One needs to be very vigilant about

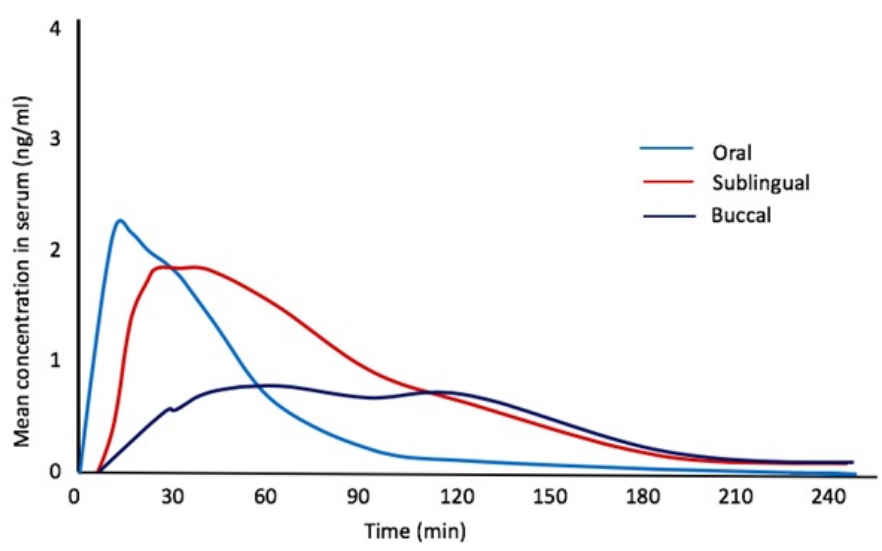

Figure 1. Mean concentrations of misoprostol acid by route over time 
hyperstimulation and uterine rupture in cases with previous caesarean section or any uterine scar in pregnancies beyond 20 weeks.

\section{Regimens: current recommendations based on the available evidence}

Mifepristone and misoprostol act synergistically in combination, and where both are available both should be used. Misoprostol alone should be used in countries where mifepristone is not available. As with early medical abortion, the goal has been to find a regimen combining the lowest doses of both drugs that is highly effective and has the fewest side effects, and which is also acceptable for women. For second trimester abortion (13-24 weeks of gestation), medical abortion with mifepristone followed by a PG analogue is an appropriate method and has been shown to be safe and effective, according to WHO and the RCOG [21].

The RCOG (Royal College of Obstetricians and gynecologists) recommended for medical abortion between 13 and 24 weeks the following regimen: Mifepristone $200 \mathrm{mg}$ orally, followed 36-48 hours later by misoprostol 800 micrograms vaginally, then 400 micrograms orally or vaginally, 3 hourly, to a maximum of four further doses. If the abortion doesn't occur, mifepristone can repeated 3 hours after the last dose of misoprostol and 12 hours later misoprostol may be recommended.

Surgical evacuation of the uterus is not required routinely following medical abortion between 13 and 24 weeks of gestation. It should be undertaken only if there is clinical evidence that the abortion is incomplete [22]. It has been well proven that pre-treatment with mifepristone $24-48 \mathrm{~h}$ before PG administration increases the success rate, shortens the induction-to-abortion interval and reduces the amount of PGs required in the second trimester [23].

Second trimester abortion in prior caesarean section patients should be carried out with caution. Analgesics should be offered to all women when required. Vaginal misoprostol or gemeprost can be administered either by the woman herself or by a clinician, according to the preference of the woman (Table 1).

Table 1. Regimens licensed, recommended or used for medical abortion

\begin{tabular}{|c|c|c|c|}
\hline Approved in: & $\begin{array}{c}\text { Mifepristone dose } \\
\text { (mg) }\end{array}$ & Prostaglandin & $\begin{array}{c}\text { Dose and route } \\
\text { of administration } \\
\text { (microg) }\end{array}$ \\
\hline $\begin{array}{c}\text { France 1991 } \\
\text { Europe and US 2000 }\end{array}$ & 600 & Misoprostol & 400 PO \\
\hline $\begin{array}{c}\text { UK 1991 } \\
\text { Sweden 1992 }\end{array}$ & 600 & $\begin{array}{c}\text { Misoprostol } \\
\text { Gemeprost }\end{array}$ & $\begin{array}{c}400 \text { PO } \\
1 \text { mg }\end{array}$ \\
\hline $\begin{array}{c}\text { Widely used } \\
\text { Guidelines }\end{array}$ & 200 & Misoprostol & 800 vaginally \\
\hline RCOG; UK 2004 & 200 & Misoprostol & $\begin{array}{c}800 \text { vaginally; } \\
800 \text { vaginally; } 400 \\
\text { repeated orally or } \\
\text { vaginally after 4 h, if } \\
\text { no expulsion }\end{array}$ \\
\hline ANAES France 2001 & 200 & Misoprostol & $\begin{array}{c}400 \text { PO or vaginally } \\
\text { repeated after 3 h if } \\
\text { no expulsion }\end{array}$ \\
\hline PPFA,US, 2005 & 200 & Misoprostol & $\begin{array}{c}800 \text { vaginally; } \\
\text { repeated within 48 h } \\
\text { if no bleeding }\end{array}$ \\
\hline WHO 2003 & 200 & Misoprostol & $\begin{array}{c}800 \text { vaginally; } 400 \\
\text { PO }\end{array}$ \\
\hline
\end{tabular}

\section{Contraindications}

There are very few absolute contraindications to medical abortion. When using a combination of mifepristone and misoprostol they include:

1. Known or suspected ectopic pregnancy

2. Previous allergic reaction to any of the drugs

3. Inherited porphyria

4. Chronic adrenal failure

5. Serious allergic asthma

6. Hemorrhagic (coagulation) disorder

\section{Caution}

Caution is required if the woman:

1. is on corticosteroid therapy

2. has severe anemia

3. has pre-existing heart disease or cardiovascular risk factors

\section{Conclusion}

In this scenario, where targeting therapy is a stronghold in clinical practice, the induced abortion in second trimester therapy should be very specific to the patient, minimizing side effects and achieving maximum results.

More studies are also needed to evaluate the optimal combination of mifepristone and misoprostol in women, evaluating the clinical history, home drug therapy, comorbidity, obstetric history with particular attention for women with prior caesarean section.

\section{Acknowledgement}

We thank our colleagues and the staff of Policlinico Umberto I of Rome.

\section{Ethic statement}

The authors declare that all data were collected meeting ethical guidelines.

\section{Disclosure statement}

The authors have no conflicts of interest.

\section{Funding sources}

There aren't funding sources

\section{Author contributions}

Conception, design, and coordination of the project: M. Monti and P. Benedetti Panici;

Collection and assembly of data: C. Pajno, S. Corno, A. Giannini, F. Clemente and D. D'Aniello;

Manuscript drafting: V. Tibaldi, G. Santangelo, C. Bracchi, V. Colagiovanni, A. Musella, V. Di Donato;

Manuscript editing: I. Palaia, G. Perniola and R. Brunelli;

Critical revision: A. Giancotti and L. Muzii;

Final approval of the manuscript: M. Monti and P. Benedetti Panici. 


\section{References}

1. Second Trimester Medical Abortion with Mifepristone-Misoprostol and Misoprosto Alone: A Review of Methods and Management doi.org/10.1016/S0968-8080(08)313718)

2. https://air.unimi.it/retrieve/handle/2434/174215/181534/Ceriotti\%20Mauri\%20 mondostetrica.pdf)

3. https://www.aogoi.it/media/3798/277-298-ivg-dopo-primi-30-giorni.pdf) legge 22 maggio 1978 - 194 art. 6

4. Kapp N, Borgatta L, Stubblefield P, Vragovic O, Moreno N (2007) Mifepristone in second-trimester medical abortion: a randomized controlled trial. Obstet Gynecol 110 1304-1310. [Crossref]

5. Laura JF, Meagan EB, Beverly W (2016) A crossover pharmacokinetic study of misoprostol by the oral, sublingual and buccal routes. Eur J Contracept Reprod Health Care.

6. World Health Organization. Safe abortion: technical and policy guidance for health systems. 2nd ed. Geneva: World Health Organization 2012.

7. Heikinheimo O (1989) Pharmacokinetics of the antiprogesterone RU 486 in women during multiple dose administration. J Steroid Biochem 32: 21-25. [Crossref]

8. Grimaldi B, Hamberger C, Tremblay D, Barre J, Tillement JP (1989) In vitro study of the binding of RU 486 and RU 42633 to human serum proteins. Prog Clin Biol Res 300: 445-448. [Crossref]

9. Khan KK, He YQ, Correia MA, Halpert JR (2002) Differential oxidation of mifepristone by cytochromes P450 3A4 and 3A5: selective inactivation of P450 3A4. Drug Metab Dispos 30: 985-990. [Crossref]

10. Soars MG, Grime K, Riley RJ (2006) Comparative analysis of substrate and inhibitor interactions with CYP3A4 and CYP3A5. Xenobiotica 36: 287-299. [Crossref]

11. Zhou SF (2008) Drugs behave as substrates, inhibitors and inducers of human cytochrome P450 3A4. Curr Drug Metab 9: 310-322. [Crossref]

12. Heikinheimo O (1990) Antiprogesterone steroid RU486. Pharmacokinetics and receptor binding in humans. Acta Obstet Gynecol Scand 69: 357-358. [Crossref]
13. Brogden RN, Goa KL, Faulds D (1993) Mifepristone. A review of its pharmacodynamic and pharmacokinetic properties, and therapeutic potential. Drugs 45: 384-409.

14. Tang OS, Gemzell-Danielsson K, Ho PC (2007) Misoprostol: Pharmacokinetic profiles, effects on the uterus and side-effects. Int J Gynaecol Obstet 99 Suppl 2: S160-S167. [Crossref]

15. Khan RU, El-Refaey H, Sharma S, Sooranna D, Stafford M (2004) Oral, rectal and vaginal pharmacokinetics of misoprostol. Obstet Gynaecol 103: 866-870. [Crossref]

16. Tang OS, Schweer H, Seyberth HW, Lee SW, Ho PC (2002) Pharmaco- kinetics of different routes of administration of misoprostol. Hum Reprod 17: 332-336. [Crossref]

17. Schaff EA, DiCenzo R, Fielding SL (2005) Comparison of misoprostol plasma concentration following buccal and sublingual admin- istration. Contraception 71: 22 25 .

18. Meckstroth KR, Whitaker AK, Bertisch S, Goldberg AB, Darney PD (2006) Misoprostol administered by epithelial routes. Obstet Gynaecol 108: 82-90. [Crossref]

19. Lalitkumar S, Bygdeman M, Gemzell-Danielsson K (2007) Mid-trimester induced abortion: a review. Hum Reprod Update 13: 37-52.

20. Royal College of Obstetricians and Gynaecologists. The Care of Women Requesting Induced Abortion. Guid, World Health Organization. Unsafe Abortion: Globa Estimates of the Incidence of Unsafe Abortion and Associated Mortality in 2000. 4th ed. Geneva7 WHO, 2004.

21. Thong KJ, Baird DT (1992) A study of gemeprost alone, dilapan or mifepristone in combination with gemeprost for the termination of second trimester pregnancy. Contraception 46: 11-17.

22. Royal College of Obstetricians and Gynaecologists. The Care of Women Requesting Induced Abortion. 7. 2011. London, Royal College of Obstetricians and Gynaecologists. Evidence-based Clinical Guideline. www.rcog.org.uk/globalassets/documents/ guidelines/abortion-guideline_web_1.pdf

23. Ho PC, Ngai SW, Liu KL, Wong GC, Lee SW (1995) Vaginal misoprostol compared with oral misoprostol in termination of second-trimester pregnancy. Obstet Gynecol 102: 648-651. [Crossref]

Copyright: (C)2020 Monti M. This is an open-access article distributed under the terms of the Creative Commons Attribution License, which permits unrestricted use, distribution, and reproduction in any medium, provided the original author and source are credited. 